\title{
Método, objeto e problema em duas tradições epistemológicas
}

Elisângela de Jesus Furtado da Silva

Mestranda em Administração pela UFMG. Membro da Associação Brasileira de Pesquisadores Negros

elisangelafurtado23@gmail.com

Laysse Fernanda Macedo dos Santos

Mestranda do Programa de Pós Graduação e Pesquisa em Administração da Universidade Federal de Minas Gerais. Administradora na Faculdade de Odontologia da Universidade Federal de Minas Gerais

layssefernanda@hotmail.com

Luiz Alex Silva Saraiva

Doutor e Mestre em Administração pela Universidade Federal de Minas Gerais.

Professor Adjunto IV do Departamento de Ciências Administrativas da Faculdade de Ciências Econômicas da Universidade Federal de Minas.

saraiva@face.ufmg.br

\section{Editor Científico: José Edson Lara}

Organização Comitê Científico

Double Blind Review pelo SEER/OJS

Recebido em 04.04.2018

Aprovado em 22.05.2018

Este trabalho foi licenciado com uma Licença Creative Commons - Atribuição - Não Comercial 3.0 Brasil 


\title{
Resumo
}

A Epistemologia é o ramo da Filosofia por meio da qual é possível refletir sobre o processo de construção do conhecimento humano. Esse é o campo do qual emerge o presente ensaio, voltado à compreensão entre método, objeto e problema na tradição epistemológica ocidental moderna sob a ótica de Karl Marx e Marx Weber. Apresentam-se as caraterísticas que marcaram a transição da Idade Média para a Idade Moderna, a fim de contextualizar as implicações que essas mudanças ocasionaram nas diversas áreas da Ciência. A discussão teórica sugere que os dois autores possuem características que revelam a influência ocidental moderna nas epistemologias consideradas centrais no processo de construção do saber científico. Para Max e Weber, o fazer científico perpassa o real acessível de forma concreta, sendo que os problemas científicos são tratados em termos de causa e efeito, por meio de metodologias pautadas na racionalidade, objetividade e neutralidade.

Palavras-chave: Epistemologia; Investigação; Max Weber; Karl Marx.

\section{Method, object and problem in two epistemological traditions}

\begin{abstract}
Epistemology is the branch of Philosophy through which it is possible to reflect on the process of building human knowledge. This is the field from which the present essay emerges, focused on the understanding between method, object and problem in the modern Western epistemological tradition from the standpoint of Karl Marx and Marx Weber. The characteristics that marked the transition from the Middle Ages to the Modern Age are presented, in order to contextualize the implications that these changes have caused in the different areas of Science. The theoretical discussion suggests that the two authors have characteristics that reveal the modern western influence in the epistemologies considered central in the process of construction of scientific knowledge. For Max and Weber, scientific doing runs through the real accessible in a concrete way, and scientific problems are treated in terms of cause and effect, through methodologies based on rationality, objectivity and neutrality.
\end{abstract}

Keywords: Epistemology; Investigation; Max Weber; Karl Marx.

\section{Método, objeto y problema en dos tradiciones epistemológicas}

\section{Resumen}

La Epistemología es la rama de la Filosofía por medio de la cual es posible reflexionar sobre el proceso de construcción del conocimiento humano. Este es el campo del que emerge el presente ensayo, orientado a la comprensión entre método, objeto y problema en la tradición epistemológica occidental moderna bajo la óptica de Karl Marx y Marx Weber. Se presentan las características que marcaron la transición de la Edad Media a la Edad Moderna, a fin de contextualizar las implicaciones que esos cambios ocasionaron en las diversas áreas de la Ciencia. La discusión teórica sugiere 
que los dos autores poseen características que revelan la influencia occidental moderna en las epistemologías consideradas centrales en el proceso de construcción del saber científico. Para Max y Weber, el hacer científico atraviesa lo real accesible de forma concreta, siendo que los problemas científicos son tratados en términos de causa y efecto, por medio de metodologías pautadas en la racionalidad, objetividad y neutralidad.

Palabras clave: Epistemología; Investigación; Max Weber; Karl Marx.

\section{Introdução}

A Epistemologia, denominada também de Teoria do Conhecimento, é o ramo da Filosofia por meio do qual é possível refletir sobre o processo de construção do conhecimento humano. Em sentido amplo, a Epistemologia estuda a natureza do conhecimento e sua justificação. De acordo com Hessen, (1999, p. 50) "o conhecimento quer dizer uma relação entre sujeito e objeto". O verdadeiro problema do conhecimento, portanto, coincide com a questão sobre a relação entre sujeito e objeto.

Numerosas reflexões epistemológicas podem ser encontradas na Filosofia antiga, especialmente em Platão e em Aristóteles. A Platão atribui-se a reflexão da "metafísica transcendente" (Reale, 2010, p. xi) e a Aristóteles, a compressão dos fenômenos empíricos. São investigações que estão embutidas em contextos subjetivos e condicionados, resultados de um processo em que determinadas narrativas se sobrepõe a outras no processo de construção do conhecimento e que denotam o desenvolvimento das bases da construção do saber científico. Esses dois teóricos são considerados importantes na consolidação e sistematização do saber filosófico, do qual decorre a Teoria do Conhecimento. Essa surge como disciplina independente somente na Idade Moderna, relacionada à história do Ocidente e que tem início após a Idade Média (Hessen, 1999).

Para Jürgen Habermas, modernidade é um fenômeno social amplo e multifacetado, concepção que diverge de outros autores que a consideram somente como resultado que mudanças estruturais e artísticas. Em sua concepção, o discurso filosófico da modernidade é inaugurado por Hegel (Habermas, 2000). Hegel desenvolveu diversos questionamentos sobre a modernidade, em busca de uma teoria que a explicasse. Ocorre que essa busca visa tanto delinear a modernidade, como também criticá-la. Em termos cronológicos, a modernidade enunciada em Hegel 
indica o período entre o Século XV e o Século XVIII. Hegel termina por estabelecer condições contextuais específicas que situam a modernidade como uma consciência entre época e razão e "que permaneceu evidente até Max Weber" (Habermas, 2000, p. 8).

Marx Weber (1864-1920) estabeleceu uma relação profunda entre o desenvolvimento do saber científico e a racionalidade própria do ocidente, ao se preocupar com a lógica do desenvolvimento econômico. Outro autor com pontos em comum com Weber é Karl Marx (1818-1883), já que se debruça na reflexão do sistema econômico, a partir do campo político, histórico e filosófico. Os dois autores lidam com questões sociais que emergem justamente da modernidade, cada qual com suas especificidades. O modo como cada um dos autores percebe a realidade, os problemas a ela relacionados e a forma de lidar com tais problemas inauguram processos considerados importantes para o desenvolvimento da pesquisa científica e atualmente ainda são referências. Em razão do exposto, justifica-se o recorte do presente estudo ao abordar a Epistemologia moderna na perspectiva de dois autores ocidentais.

Tendo em vista a importância de conduzir o leitor em uma linha de pensamento concatenado, antes de abordar a temática principal desse estudo, resolveu-se explicitar os principais aspectos relacionados ao conceito, história e aplicação da Epistemologia. Considerando também o recorte temporal, apresentam-se as caraterísticas que marcaram a transição da Idade Média para a Idade Moderna, a fim de contextualizar as implicações que essas mudanças ocasionaram nas diversas áreas da Ciência. Uma vez apresentado esse contexto basilar, discorre-se a respeito da relação entre método, objeto e problema na tradição epistemológica ocidental moderna segundo Karl Marx e Max Weber. Por fim, apresentam-se as considerações finais decorrentes do ensaio.

\section{Fundamentação Teórica}

O tratamento teórico de uma temática deve obedecer a algumas premissas como forma de se cercarem as diferentes concepções, de modo a possibilitar uma visão panorâmica dos conceitos, como forma de entendê-los. Diante disso, aborda-se a seguir o conceito de Epistemologia, o surgimento, significado e as principais correntes atuais. Em seguida, está descrito o processo histórico que apresentou uma 
forte ruptura na forma como o conhecimento era produzido até então, período marcado pela transição da Era Medieval para a Moderna. Logo após, é apresentada uma discussão sobre como se dá a Relação entre método, objeto e problema na tradição epistemológica ocidental moderna na visão de Karl Marx e Max Weber.

\subsection{Epistemologia: conceito, história e aplicação}

Os alemães foram os primeiros a perceberem a possibilidade de haver uma teoria capaz de ser base para a construção do saber científico. O professor alemão lecionava por meio do conhecimento teórico produzido, o que levou a uma reflexão a respeito da teoria da ciência ou theorie erkenntniss, no original em alemão. O livro Fundamentos da Geometria é o primeiro a usar o termo epistemologia com o sentido equivalente ao theorie erkenntniss alemão no final do século XIX. O autor dessa obra é Bertrand Russell, galês, matemático, filósofo e lógico, nascido em 1970 (Garcia, 2006).

Russell questiona o realismo ingênuo, pela crença sem resistência que o mundo é um estado de coisas tal como ele se apresenta, ou em outras palavras, as coisas existem por si mesmas. O questionamento do autor tem relação com pesquisas realizadas na época na área da física, como a de Einstein no Brasil, por evento de um eclipse solar, que levou à confirmação da Teoria da Relatividade (Johnson, 2001). Esse e outros estudos levaram a um dilema: a física e o realismo ingênuo não poderiam estar corretos ao mesmo tempo (Garcia, 2006). Esse dilema inaugura a possibilidade de se construir conhecimento de outras formas, até então não problematizadas.

O termo epistemologia é usado para se referir à teoria da ciência ou filosofia da ciência e pode ser entendida como a forma como se conhece o mundo. Conhecer, para Hessen (1999, p. 97) "significa apreender espiritualmente um objeto". A apreensão do objeto pode ocorrer de diversas formas. Essa forma irá determinar o modo que se utiliza para descrever e analisar o real, modo que caracteriza a produção do conhecimento. Por muito tempo, a epistemologia refletia de forma preponderante o ideal europeu de produção de conhecimento. Atualmente existem diversas epistemologias, dentre os quais o Positivismo, Estruturalismo, Humanismo Radical, Interpretativismo, Construtivismo e Pós-Estruturalismo, para citar algumas. 
O positivismo dialoga diretamente com ontologia realista (Rees, 2008). De acordo com essa visão, a produção do conhecimento deve se valer de instrumentos para quantificar, numerar e classificar os objetos como forma de se aproximar da sua realidade sem interferir em sua essência ou natureza. Na perspectiva estruturalista, a realidade só pode ser conhecida de forma estrutural, sendo as estruturas definidas por meio das relações sociais. Um dos autores que refletem sobre essa concepção é Karl Marx. O autor admite que a sociedade se divide em somente duas categorias dialéticas, capital e trabalho; essa noção é uma das características do estruturalismo (Marx, 2013).

De acordo com Humanismo Radical, o real é algo somente acessível a partir do ser humano, ou seja, o processo de compreensão da realidade é influenciado e condicionado à consciência humana (Amboni, Caminha, Andrade, \& Fernandes, 2016). Já na visão interpretativista, a centralidade do conhecimento está no sujeito, e o real é o que ele interpreta do mundo à sua volta. O Construcionismo é mais uma via epistemológica possível, entendendo que o indivíduo, dotado de uma essência, é centro do processo de construção do conhecimento. A corrente pós-estruturalista admite que todas as possibilidades podem acontecer ao mesmo tempo na produção do conhecimento. Não existe uma identidade ou numa essência que defina os objetos. O que nos define é um misto entre o processo histórico, contexto social além de outras diversas variáveis. Essa corrente privilegia o lugar de fala e os discursos como elementos importantes na produção de determinado conhecimento.

O Humanismo Radical, o Interpretativismo e o Construcionismo são fruto de um processo de desenvolvimento histórico a respeito da construção do conhecimento e consequentemente do saber científico e que dizem respeito a formas distintas de se perceber e compreender o mundo e a realidade. Tratam-se, portanto, de possibilidades epistemológicas e que fundamentam a criação de teorias. Para entender o processo que levou ao atual panorama epistemológico, é importante recuperar os antecedentes históricos que levaram a tal situação, explicitado no capítulo posterior.

\subsection{Transição da Era Medieval para a Era Moderna}


Tendo em vista a questão central do presente estudo, que consiste em analisar a relação problema, objeto e método sob a ótica de dois autores/ correntes epistemológicas da modernidade ocidental, torna-se relevante discorrer a respeito das caraterísticas que marcaram a transição da Era Medieval para a Era Moderna, bem como suas implicações nas diversas áreas da Ciência, a fim de contextualizar o pensamento epistemológico que será apresentado adiante.

A transição do feudalismo ao capitalismo foi marcada por inúmeras mudanças. Surgiram diferenças entre o trabalho dos escravos e o trabalho dos servos. A melhoria da produção não interessava aos primeiros porque nada mais receberiam pelo seu acréscimo. Para os segundos, porém, a melhoria possibilitava o acesso a uma parte maior da riqueza produzida. As melhorias do trabalho servil originaram um excedente e o comércio foi se intensificando, levando à acumulação do capital mercantil. Por outro lado, a acumulação desse capital também era impulsionada pelo intercâmbio cada vez mais intenso, proporcionado especialmente pelas cruzadas e por outros eventos entre a Europa e o Oriente (Tonet, 2013).

O desenvolvimento das forças produtivas impulsionou as grandes navegações e as grandes descobertas científicas, que culminaram na criação de gigantescas forças produtivas, capazes de gerar, em curto espaço de tempo, com a Revolução Industrial, uma riqueza capaz de satisfazer as necessidades da humanidade (Tonet, 2013).

Essas transformações econômicas também ocasionaram profundas mudanças em outras áreas da atividade humana como, por exemplo, nas dimensões políticas, artísticas, jurídicas, sociais, ideológicas, educativas, filosóficas, científicas. Nesse sentido, destacam-se aqui três momentos-chave da passagem do medieval para o moderno: o Renascimento, o lluminismo e a Reforma Protestante.

O Renascimento marca o início da Idade Moderna. O desenvolvimento comercial e a agitada atividade cultural no Ocidente, sobretudo no século XV, faz surgir o movimento intelectual centrado no Homem. Essa mudança de mentalidade pode ser percebida nos humanistas, os quais buscaram na Antiguidade recuperar a cultura greco-romana, a qual representava - para eles - o ideário perfeito de civilização (Giovanazzi, 2014). Le Goff (2015) salienta que diferentemente da Idade Média, em que o indivíduo se encontrava limitado pela religião, pelo ambiente social, 
pelas práticas comunitárias, o homem do Renascimento pode, sem entraves, desenvolver sua personalidade.

Por sua vez, o lluminismo foi um movimento cultural europeu no século XVIII que procurou mobilizar o poder da razão, a fim de reformar a sociedade e o conhecimento herdado da tradição medieval. Buscava um conhecimento profundo da natureza, com o objetivo de torná-la útil ao homem moderno. O lluminismo defendia a racionalidade imanente a todos os indivíduos e, portanto, a sua capacidade de conhecer verdadeiramente a realidade tanto natural como social.

A Reforma Protestante e a Contrarreforma Católica ocasionaram um grande impacto social, reconfiguraram o mapa político europeu e jogaram o continente em séculos sangrentos que culminaram com a Guerra dos Trinta Anos (1618-1648). A Idade Média foi uma época profundamente religiosa, marcada pelo poderio da Igreja, pela força de uma devoção quase geral. O século XVI trouxe a ruptura da reforma e conheceu ferozes guerras motivadas por religião. A fé cristã apresenta-se sob ao menos duas formas, a católica tradicional e a reformada, que também é chamada de protestante e que compreende diversas orientações: anglicanismo na Grã-Bretanha, luteranismo e calvinismo.

Uma das esferas em que se refletiu fortemente esse conjunto de transformações foi a área do conhecimento. A emergência de uma nova forma de sociabilidade, de um novo mundo, impunha também a estruturação de uma nova forma de produzir conhecimento (Tonet, 2013). Tais mudanças impactaram profundamente a relação problema, objeto e método, o que será debatido a seguir, considerando a epistemologia moderna sob a ótica de Karl Marx e Weber.

\subsection{Relação entre método, objeto e problema na tradição epistemológica ocidental moderna}

As mudanças percebidas entre as Eras Medieval e Moderna podem ser problematizadas em uma perspectiva geográfica. A preocupação com o conhecimento e sua forma de produção é algo enraizado na sociedade ocidental. Esse legado teve início na Grécia Clássica. As principais características dessa nova concepção dizem respeito ao racionalismo e à posição crítica. Com o fim do domínio religioso sobre o processo de construção do conhecimento, a ciência e a filosofia emergiram como áreas com possibilidade ao amplo debate e contraste das ideias. 
O debate só é possível quando o que sustenta as ideias não são dogmas inquestionáveis, mas sim informações construídas por meio de códigos amplamente conhecidos. A oposição radical às crenças religiosas tidas como imutáveis, absolutas e inquestionáveis deu origem a um movimento que privilegiou a racionalidade. $\mathrm{O}$ desenvolvimento da ciência na sociedade ocidental moderna pautou-se por uma epistemologia própria, em que os pilares da construção do conhecimento fossem racionais e objetivos (Willians, 2001).

Infere-se que o conhecimento considerado legítimo era aquele que poderia ser quantificado e categorizado, possibilitando a análise. Para tanto, as pesquisas se valem de métodos que são a linguagem comum e que possibilitam amplamente a comparação e o confronto de ideias. Os objetos passíveis de estudos são aqueles que podem ser medidos, por meio de um sistema. Já os problemas selecionados são aqueles que demandam ordenamento, e o seu tratamento deve estabelecer uma relação de causa e efeito. Dois grandes representantes dessa concepção são Karl Marx e Max Weber, cujas ideias são discutidas a seguir.

\subsubsection{Relação entre método, objeto e problema na tradição epistemológica ocidental moderna segundo Karl Marx}

Karl Marx nasceu em Trèves, no dia 5 de maio de 1818, e faleceu em Londres, no dia 14 de março de 1883. Marx foi um filósofo e revolucionário socialista alemão. Criou as bases da doutrina comunista e sua filosofia exerceu influência em várias áreas do conhecimento, tais como Sociologia, Política, Direito, Teologia, Filosofia e Economia.

No presente estudo a relação entre método, objeto e problema na tradição epistemológica ocidental moderna, segundo Karl Marx, será apresentada de acordo com os fundamentos constantes em O Capital. O Capital é um conjunto de livros de Karl Marx que constitui uma análise sobre o capitalismo. O primeiro livro desse conjunto foi publicado em 1867 e foi intitulado de O Processo de Produção do Capital. Para muitos, essa obra é o marco do pensamento socialista marxista. Nela estão presentes os aspectos do modo de produção capitalista e muitos conceitos econômicos complexos como, por exemplo, os conceitos de mais valia, capital constante, capital variável e acumulação primitiva. O segundo livro, O processo de 
circulação do capital, foi publicado em 1885. A terceira obra que compõe O Capital é denominada $O$ processo global da produção capitalista e foi lançada em 1894. Por fim, em 1905 foi publicada a obra intitulada Teorias da mais valia.

O ponto de partida da investigação (problema de investigação) de Marx é a produção material em um determinado estágio do desenvolvimento social-humano, mas não a produção em geral, que não só é uma abstração genérica, pobre e vazia, como também apologética. Nesse sentido, Marx, evocado por Chagas (2011, p. 65), destaca que:

[...] indivíduos que produzem em sociedade, portanto produção de indivíduos socialmente determinada é, naturalmente, o ponto de partida. O caçador e o pescador individuais e isolados, com que começam Smith e Ricardo, pertencem às imaginações carentes de fantasia do século XVIII. São "robinsonadas" que não expressam de forma alguma, como imaginam alguns historiadores da cultura, uma simples reação contra os excessos de requinte e um retorno a uma vida natural mal compreendida. Do mesmo modo, o contrato social de Rousseau, que estabelece, entre sujeitos independentes por natureza, relações e laços por meio de um pacto, nem por isso se baseia num tal naturalismo. Isto é aparência, e somente aparência estética das pequenas e grandes robinsonadas. Na realidade, trata-se de uma antecipação da "sociedade burguesa" que se vinha preparando desde o século XVI, dando passos gigantescos para a sua maturidade no século XVIII.

Ao mostrar que a produção material não é uma produção, em geral, abstrata, mas é socialmente determinada, Marx delimita seu objeto de investigação, a saber, a produção burguesa moderna, e defende o argumento de que nela os indivíduos não podem ser tomados, como aparecem na economia política, atomisticamente, já que eles são membros de um conjunto social, ou seja, se encontram interligados por meio de relações complexas que determinam seu ser social (Chagas, 2011).

Nos textos introdutores do Livro I de O Capital, Gorender (2013, p.61) destaca que o objeto da obra é

[...] o modo de produção capitalista e as relações de produção e de circulação que lhe correspondem. Ora, trata-se de um objeto abstrato. De fato, e apesar das aparências, Marx não analisa uma "sociedade concreta", nem mesmo a Inglaterra, da qual ele fala insistentemente no Livro I, mas o modo de produção capitalista e nada mais. Esse objeto é abstrato: isso significa que ele é terrivelmente real e nunca existe em estado puro, porque só existe em sociedades capitalistas. Simplesmente: para poder analisar essas sociedades capitalistas concretas (Inglaterra, França, Rússia etc.), é necessário saber que elas são dominadas por essa realidade terrivelmente concreta e "invisível" (a olhos nus) que é o modo de produção capitalista. "Invisível", portanto, abstrata. 
Marx demonstra que a produção burguesa moderna é um todo orgânico, dinâmica, rica totalidade de relações diversas, na qual seus momentos constitutivos, a distribuição, a troca e o consumo, estão concatenados entre si, formando unidade sintética, e ao mesmo tempo contraditória: a produção oferece, na forma material, o seu objeto, ou seja, os elementos materiais do consumo, pois, sem objeto não há consumo. A produção determina, porém, não só a forma objetiva, como também subjetiva do objeto (Chagas, 2011).

Karl Marx lançou uma perspectiva radicalmente nova de mundo e consequentemente de fazer ciência e filosofia. Diferente de outros autores modernos como Descartes, Bacon, Galileu, Hume e Kant, Marx não escreveu nenhuma obra específica sobre a problemática do método científico. Há, apenas, referências esparsas à questão do método, nos Manuscritos Econômico-Filosóficos, em $A$ Sagrada Família, na Miséria da Filosofia, em A ideologia Alemã, em O Capital e no Posfácio à $2^{\underline{a}}$ edição alemã de $O$ Capital. Além disso, há também as famosas páginas sobre o método da economia política encontradas tanto nos Grundrisse como na Introdução Geral à Crítica da Economia Política, de 1857 (Tonet, 2013).

Para Marx não há um método que possa ser apreendido previamente ao ato do conhecimento. Desse modo,

[...] se por método se entende, como é o sentido mais comum que este conceito adquiriu a partir da perspectiva gnosiológica moderna, um conjunto de regras e procedimentos previamente estabelecidos, que podem ser apreendidos separadamente do objeto e que serão aplicados na realização do conhecimento, então, de fato, não existe método na perspectiva de Marx (Tonet, 2013, p. 72).

Coerente com essa perspectiva, Chasin (2009, p. 89) salienta que "se por método se entende uma arrumação operativa, a priori, da subjetividade, consubstanciada por um conjunto normativo de procedimentos, ditos científicos, com os quais o investigador deve levar a cabo seu trabalho, então, não há método em Marx.".

Surge, então, o seguinte questionamento: Por que não existe método, no sentido entendido pela metodologia científica moderna, para Marx? Esse autor não objetivava entender o método apenas como método. Para Marx não importava somente descobrir a lei que regia os fenômenos investigados, mas, sobretudo "a lei 
de sua modificação, de seu desenvolvimento, isto é, a transição de uma forma a outra, de uma ordem de inter-relação a outra" (Marx, 2013, p. 126).

No Posfácio da segunda edição Alemã de O Capital, Marx destaca que o método aplicado na obra foi pouco compreendido, dada a existência de interpretações contraditórias sobre o livro. Alguns críticos o culparam de tratar a economia metafisicamente, ao passo que outros o acusaram de ter se limitado à mera dissecação crítica do dado, em vez de prescrever receitas para o cardápio da taberna do futuro (Marx, 2013).

Nas palavras de Chagas, (2011, p. 5):

[...] o método dialético de Marx tem como sujeito o próprio real, a lógica da coisa e não a coisa da lógica, do conceito, razão pela qual ele nem é um método subjetivista, tal como o idealismo especulativo acrítico e abstrato, que pressupõe um pensamento autonomizado enquanto demiurgo do real, isto é, um sujeito que dá, a partir da ideia, sentido à realidade, tomando-a como um caos desordenado, nem um método puramente objetivo, como o empirismo acrítico, o positivismo, que toma o pensamento como atividade passiva e a realidade como algo já acabado, pronto, dada imediatamente pela experiência direta, assumindo e ratificando ingenuamente a sua existência empírica, positiva.

Marx destaca que o fundamento da dialética de seu método não é apenas diferente de Hegel, mas é exatamente o seu oposto. Para Hegel, o processo de pensamento chega a transformar num sujeito autônomo, é o demiurgo do processo efetivo, o qual constitui apenas a manifestação externa do primeiro. Já para Marx, o ideal não é mais do que o material transposto e traduzido na cabeça do homem (Marx, 2013).

Karl Marx critica a concepção dialética idealista de Hegel por atribuir ao espírito (uma entidade mística) a responsabilidade pelo desenvolvimento da história humana. Ao contrário de Hegel, Marx propôs outro sistema, o materialismo dialético. Se o sistema hegeliano fazia tudo derivar da ideia absoluta, Marx defende que a consciência, o pensamento, a ideia são reflexos da realidade material (Vasconcelos, 2014).

Para Chagas, 2011 o método de Marx é um valioso procedimento de investigação e crítica ao método positivista da economia clássica e ao método formal da dialética hegeliana, por permanecerem estreitos, seja pela empiria imediata, pela exterioridade inerte, seja pelo pensamento, pela pura interioridade espiritual, no 
abstracionismo, exteriores à realidade efetiva, sendo incapazes de apreendê-la a partir de suas determinações histórico sociais.

O método dialético de Marx pressupõe dois momentos inseparáveis: a investigação (ou a pesquisa) e a exposição (ou a apresentação). A investigação é o esforço prévio de apropriação, pelo pensamento, das determinações do conteúdo do objeto no próprio objeto, quer dizer, uma apropriação analítica e reflexiva do objeto pesquisado antes de sua exposição metódica. Por sua vez, a exposição, não é simplesmente uma auto exposição do objeto, senão ele seria acrítico, mas é uma exposição crítica do objeto com base em suas contradições, ou seja, uma exposição crítico-objetiva da lógica interna do objeto, do movimento efetivo do próprio conteúdo do objeto (Chagas, 2011).

Nas palavras de Chagas (2011), a dialética de Marx não é um instrumento, uma técnica de intervenção externa do pensamento ao objeto, como que um caminho pelo qual o pensamento manipula, a partir de hipóteses exteriores, o objeto. Na verdade, o pensamento deve se livrar de opiniões pré-concebidas, de conceitos externos ao objeto, de hipóteses que pairam acima dele, para nele mergulhar e penetrá-lo, considerando apenas o seu movimento, para trazer à consciência esse trabalho da própria lógica específica do objeto específico.

Em suma, o método de Marx é o método da reconstrução do real através do pensamento e da exposição (ou apresentação) crítica desse próprio real. Esse método de pesquisa (reconstrução) e exposição (apresentação) do real é reafirmado por Marx, no posfácio de $O$ Capital, conforme trecho a seguir:

Deve-se, sem dúvida, distinguir, formalmente, o método de exposição do método de pesquisa. A investigação tem de apoderar-se da matéria, em seus pormenores, de analisar suas diferentes formas de desenvolvimento e de descobrir a conexão interna que há entre elas. Só depois de concluído esse trabalho, é que se pode apresentar, adequadamente, o movimento real. Se isto se consegue, ficará espelhada, no plano ideal, a vida da realidade pesquisada. (Marx, 2013, p.128).

\subsubsection{Relação entre método, objeto e problema na tradição epistemológica ocidental moderna segundo Max Weber}

Max Weber nasceu em 1864 na Alemanha. Weber foi advogado, sociólogo, economista e professor. Dentre suas maiores obras, podem-se destacar Economia e Sociedade e a Ética Protestante e o Espírito do Capitalismo. Weber é considerado 
uma grande referência no campo das Ciências Sociais. Ele faleceu em 1920, em função de uma pneumonia, na cidade de Munique, Alemanha.

Weber acreditava que o saber científico produzido no ocidente pode ser tido como válido, considerando-se seu grau de desenvolvimento. Muitas civilizações se valeram da dualidade entre conhecimento e observação na produção científica, mas a ausência de meios matemáticos para explicar os fenômenos é determinante para o autor considerar mais legítimo o conhecimento produzido no ocidente em relação aos demais (Weber, 2004).

A concepção weberiana tem uma razão de ser. Diferenciar a produção de conhecimento e classificar como mais legítimos os autores que se valeram de métodos matemáticos revelam a lógica defendida pelo autor de como o conhecimento é produzido, quais as formas possíveis de acessar o real e como deve ocorrer a análise para a produção do conhecimento. $O$ ponto inicial para compreensão do pensamento do autor diz respeito ao problema, ou seja, como emergem as questões dignas de tratamento científico.

Em Ciência como Vocação, Weber relata que o problema inicial que o direcionou consiste na seguinte questão: "Quais são as condições da ciência como vocação no sentido material da expressão? " (Weber, 1982, p. 155). A formulação da questão demonstra a preocupação do autor com as circunstâncias concretas que permeiam o exercício profissional da ciência. Seu olhar para as questões concretas surge a partir da lógica de produção do conhecimento, considerada por ele como legítima. Para Weber, os problemas emergem de questões materiais porque são elas que determinam a vida das pessoas. A análise de problemas sociais inevitavelmente pode revelar a forma defendida de constituição dessa sociedade pelo autor da análise.

No posicionamento de Weber está implícita uma concepção ontológica, descrita por Hessen (1999) como realista. Sob a perspectiva axiomática (verdades consideradas universais) teóricos que adotam essa postura acreditam que o objeto de uma pesquisa possui características reais, concretas, que o determinam e que tais elementos o definem, independente do pensamento de quem o observa. Dessa forma, a centralidade da produção do conhecimento está no objeto. Os problemas formulados nessa visão tenderão a buscar a origem e causa dos problemas sociais (Venables, 2016). A partir da formulação das questões, as formas possíveis de serem resolvidas já terão um direcionamento. 
Considerando a concretude de um fenômeno, a forma de acesso aos dados do problema deverá se valer de métodos que neutralizem ou ao menos minimizem a subjetividade do pesquisador sobre o objeto. Weber (1982, p.172) evidencia tal posicionamento no trecho "Deixar que os fatos falem por si é a forma mais parcial". A neutralidade é tida como um posicionamento ético do cientista, que deve se valer dos meios necessários para se distanciar do seu objeto de modo que não produza conceitos enviesados ou contaminados sobre o mesmo. Essa postura é muito utilizada nas ciências naturais, como na Física que concebe o mundo em termos totalmente quantitativos (Hessen, 1999).

Para Weber, explicitar os fatos deve ser algo feito de modo matemático e lógico, já que entende que dessa forma, a visão ou crença particular do cientista estarão afastadas dos resultados obtidos (Weber, 1982). Se uma inferência não possui uma via lógica de construção, ela pode ser tida como demagogia ou crença religiosa. Uma vez entendida a necessidade de que a descrição dos fatos deve se ater aos mesmos, e sua análise deve se valer de meios matemáticos, pretende-se produzir um conhecimento que seja neutro.

Oliveira (2008) demonstra a construção do percurso da produção científica. Para que ocorra o avanço do conhecimento, o cientista deve primeiro se debruçar sobre a seleção dos fenômenos sociais passíveis de investigação. Cada cientista estará sensível ou não para os problemas sociais, e os que lhes são visíveis são aqueles que podem ser explicados considerando o repertório em um determinado campo. problema selecionado pelo cientista possui características que podem definir quais teorias podem explicá-lo ou não. Superado o tratamento teórico do problema, o leque metodológico com capacidade para explorar o fenômeno estará dado.

O percurso adotado por Weber pode ser entendido nas teses que pautam a construção científica neutra, como salienta Oliveira (2008):

1. Tese da neutralidade temática: a ciência é neutra porque o direcionamento da pesquisa científica, isto é, a escolha dos temas e problemas a serem investigados, responde apenas ao interesse em desenvolver o conhecimento como um fim em si mesmo.

2. Tese da neutralidade metodológica: a ciência é neutra porque procede de acordo com o método científico, segundo o qual a escolha racional entre as 
teorias não deve envolver, e de maneira geral não tem envolvido, valores sociais.

3. Tese da neutralidade factual: a ciência é neutra porque não envolve juízos de valor; ela apenas descreve a realidade, sem fazer prescrições; suas proposições são puramente factuais.

Ao refletir sobre a ciência sem pressupostos, Weber (1982, p. 170) chega a questionar se tal postura seja possível. Ele ressalta que existe uma crença de que "a ciência pressupõe, ainda, que o produto do trabalho científico é importante no sentido de que vale a pena conhecê-lo". Oliveira (2008) descreve essa premissa na tese da neutralidade temática, por meio da qual é possível admitir que a ciência goza de autonomia para a escolha das questões dignas de tratamento.

Tendo como base a intenção da imparcialidade na produção científica, a tese da neutralidade metodológica seria a forma de acesso aos dados de forma a legitimar o conhecimento produzido, já que para a realização do mesmo utilizou-se de mecanismos amplamente aceitos e testados para a coleta de dados. É possível perceber que o pensamento weberiano privilegia metodologias com abordagem quantitativas, uma vez que essas se utilizam de modelos matemáticos e racionais para explicar fenômenos sociais.

No que se refere à neutralidade factual, Weber a reforça categoricamente. Para ele "[...] o verdadeiro professor evitará impor, da sua cátedra, qualquer posição política ao aluno, quer seja ela expressa ou sugerida" (Weber, 1982, p. 172). Sustentar um posicionamento científico e outros de naturezas distintas é considerado algo ambíguo para o autor, inferência possível a partir de sua indagação de "a qual dos deuses em luta serviremos? " (Weber, 1982, p 180). O autor é enfático ao dizer que a sala de aula, lugar de compartilhar e produzir conhecimento, não é o local adequado para evidenciar posicionamento político.

Diante do exposto, observa-se que Weber defende a produção do conhecimento a partir de uma concepção de real possível de ser matematizado e compreendido por vias racionais. Contudo, ao questionar posições tradicionais à época, como a crença romântica de Platão de ciência enquanto luz sobre as trevas em sua obra $\mathrm{Da}$ República, Weber demonstra certas inconsistências, quando aborda a questão do valor da ciência. 
Para Weiss (2014), Weber é crucial para a adoção da objetividade em Ciências Sociais. Para tanto, o autor elenca o que seriam duas grandes contribuições para área. A primeira se refere à exortação de que os cientistas sociais não devem usar recursos que exponham um posicionamento pessoal, um juízo de valor. Já a segunda se refere a um aspecto metodológico, uma vez que, para ele, a pesquisa social deve confrontar os argumentos e hipóteses por meio do estabelecimento de relações causais dos problemas.

Com relação ao valor ou juízo de valor, em Ensaios de Sociologia o autor faz referência diversas vezes ao termo. A noção de valor é algo que inevitavelmente estará ligada à subjetividade dos sujeitos. Valorar fenômenos é um exercício que irá acionar as vivências, experiências e conhecimentos acumulados de cada indivíduo. Dessa forma, se a noção de valor é algo central na construção do conhecimento, a neutralidade cientifica é algo que pode ser questionado.

Weber conclui que a simples análise dos fatos objetivos já configura um reducionismo do potencial científico, e que é esperado que esse campo aponte formas de como os indivíduos devem viver. Evocando Tolstói, ele diz "se a ciência não dá, quem dará resposta à pergunta que faremos e como disporemos nossas vidas?" (Weber, 1982, p. 180). O questionamento revela que existem limites para a pretensão racional de produção e uso do discurso científico.

\section{Considerações Finais}

O presente estudo buscou abordar relação entre método, objeto e problema na tradição epistemológica ocidental moderna na perspectiva de Karl Marx e Marx Weber. Entender a episteme presente nos dois autores passa pelo processo de compressão do processo histórico que influenciou o pensamento ocidental moderno. A transição entre as Eras Medieval e Moderna foi pautada por profundas transformações sociais, que influenciaram o processo de construção do conhecimento científico. A emergência de uma nova forma de sociabilidade, de um novo mundo, impunha também a estruturação de uma nova forma de produzir conhecimento.

As mudanças percebidas entre as Eras Medieval e Moderna podem ser problematizadas em uma perspectiva geográfica. A preocupação com o conhecimento e sua forma de produção é algo enraizado na sociedade ocidental. A oposição radical 
às crenças religiosas tidas como imutáveis, absolutas e inquestionáveis deu origem a um movimento que privilegiou a racionalidade. O desenvolvimento da ciência na sociedade ocidental moderna pautou-se por uma epistemologia própria, em que os pilares da construção do conhecimento fossem racionais e objetivos.

Infere-se a partir de então que o conhecimento considerado legítimo é aquele que pode ser quantificado e categorizado, possibilitando a análise. Para tanto, as pesquisas se valem de métodos que utilizam uma linguagem comum e que possibilitam amplamente a comparação e o confronto de ideias. Os métodos devem ser capazes de conferir neutralidade ao estudo, minimizando a influência do pesquisador sobre o pesquisado. Os objetos passíveis de estudos são aqueles que podem ser medidos, por meio de um sistema. Já os problemas selecionados são aqueles que demandam ordenamento, e o seu tratamento deve estabelecer uma relação de causa e efeito. Dois grandes representantes dessa concepção são Karl Marx e Max Weber.

Para Marx, a investigação é limitada ao que é material, ou seja, o universo pesquisável é dado pela materialidade das coisas e que elas são socialmente determinadas. Karl Marx lançou uma perspectiva radicalmente nova de mundo e consequentemente de fazer ciência e filosofia. Para ele, não há um método que possa ser apreendido previamente ao ato do conhecimento. Ele acredita que é mais importante descobrir a lei da modificação dos fenômenos do que as leis gerais que os regem. O método implícito em sua obra pode ser entendido como sendo a reconstrução do real através do pensamento e da exposição (ou apresentação) crítica desse próprio real.

Weber percebe as ciências de forma hierarquizada, de forma que a ocidental é considerada como válida, por usar meios matemáticos para explicar os fenômenos, diferente dos processos de construção do conhecimento percebidos em outras civilizações. Ele entende que os problemas emergem de questões materiais porque são elas que determinam a vida das pessoas. Considerando a concretude de um fenômeno, a forma de acesso aos dados do problema deverá se valer de métodos que neutralizem ou ao menos minimizem a subjetividade do pesquisador sobre 0 objeto. Explicitar os fatos deve ser algo feito de modo matemático e lógico, já que entende que, dessa forma, a visão ou crença particular do cientista estarão afastadas dos resultados obtidos. É possível perceber que o pensamento weberiano privilegia 
metodologias com abordagem quantitativas, uma vez que essas se utilizam de modelos matemáticos e racionais para explicar fenômenos sociais.

Os dois autores possuem características que revelam a influência ocidental moderna nas epistemologias consideradas centrais. Para eles, o fazer científico perpassa o real que é material. A racionalidade ocidental possui como premissa o ordenamento das coisas. Os problemas são tratados em termos de causa e efeito, por meio de metodologias pautadas na racionalidade, objetividade e neutralidade.

A via racional é vista como uma das possíveis para a produção do conhecimento. Porém, não deve ser vista como única. A própria lógica racional possui limites, uma vez que é impossível dissociar a subjetividade da produção humana. Percebe-se que a adoção de premissas das ciências naturais às ciências humanas é algo que foi feito como forma de legitimá-la enquanto ciência. As leis que se aplicam às ciências naturais já passaram por diversos processos de mudança, e o que deve ser entendido é que, se os métodos racionais matematizados não garantem um conhecimento que seja universal e absoluto, o mesmo ocorre para as ciências sociais. Essa deve se valer de uma epistemologia própria, livre da noção hierarquizada que tem pautado a pesquisa social atualmente.

\section{Referências}

Amboni, N., Caminha, D. O. Andrade, R. O. B., \& Fernandes, M. (2017). Abordagem multiparadigmática em estudos organizacionais: avanços e limitações. Revista de Administração da Universidade Federal de Santa Maria, 10(5), 808-827.

Chagas, E. F. (2011). O método dialético de Marx: investigação e exposição crítica do objeto. Revista Síntese, 38(120), 55-70.

Chasin, J. (2009). Marx - estatuto ontológico e resolução metodológica. São Paulo: Boitempo.

García, R. (2006). Epistemología y teoría del conocimiento. Salud Colectiva, 2(2), 113-122.

Giovanazzi, M. C. P. M. (2014). Renascimento: Uma Ruptura Medieval ou Continuidade Moderna? Revista História, Imagem e Narrativas, 18, 1-12.

Gorender, J. (2013). Apresentação. In K. Marx. O capital: crítica da economia política. São Paulo: Boitempo Editorial, pp. 20-85.

Habermas, J. (2000). O discurso filosófico da Modernidade. São Paulo: Martins Fontes. 
Hessen, J. (1999). Teoria do conhecimento. São Paulo: Martins Fontes.

Johnson, P. (2001). Modern Times: The World form the Twenties to the Nineties (Revised Edition). Nova lorque: Perennial Classics.

Le Goff, J. (2015). A História deve ser dividida em pedaços? São Paulo: Editora UNESP.

Marx, K. (2013). O capital: crítica da economia política. São Paulo: Boitempo Editorial.

Oliveira, M. B. (2008). Neutralidade da ciência, desencantamento do mundo e controle da natureza. Revista Scientiae Studia, 6(1), 97-116.

Reale, G. (2010). História da filosofia grega e romana-Aristóteles. São Paulo: Edições Loyola.

Rees, D. K. (2008). Considerações sobre a pesquisa qualitativa. Revista Signótica, 20(2). DOI: https://doi.org/10.5216/sig.v20i2.6095.

Repa, L. (2010). Hegel, Habermas e a modernidade. Revista Dois Pontos, 7(4), 151162.

Tonet, I. (2013). Método científico: uma abordagem ontológica. São Paulo: Instituto Lukács.

Vasconcelos, F. A. (2017). A dialética em Marx. Saberes Interdisciplinares, 13, 99120.

Venables, J. P. (2016). Aportes para una ontología social realista. Cinta de Moebio, 56, $172-186$.

Weber, M. (2004). A ética protestante e o "espírito" do capitalismo. São Paulo: Companhia das Letras.

Weber, M. (1982). Ensaios de sociologia. Rio de Janeiro: Zahar.

Weiss, R. (2014). Max Weber e o problema dos valores: as justificativas para a neutralidade axiológica. Revista de Sociologia e Política, 22, 113-137.

Williams, M. (2001). Problems of knowledge: a critical introduction to epistemology. Reino Unido: Oxford University Press. 